\author{
Cadernos de \\ ESTUDOS LINGï̈ISTICOS - (55.2), Campinas, Jul./Dez. 2013
}

\title{
O MATERIAL DIDÁTICO DE INGLÊS DA REDE PÚBLICA ESTADUAL PAULISTA: PRODUÇÃO DE SENTIDOS NA PERSPECTIVA DA ANÁLISE DE DISCURSO DE LINHA FRANCESA
}

\author{
MAISA DE ALCÂNTARA ZAKIR*
}

\begin{abstract}
RESUMO: O objetivo deste artigo é analisar os sentidos produzidos por professores de inglês da rede pública estadual paulista, participantes de uma turma de um curso semipresencial de especialização lato sensu, sobre o material didático de inglês distribuído pela Secretaria de Estado da Educação. A partir da perspectiva teórica da Análise de Discurso de linha francesa, buscamos compreender o que os professores de inglês pensam sobre o material com o qual trabalham em suas aulas e analisar as posições-sujeito que ocupam nesse contexto. Os dados analisados consistem em postagens de um fórum virtual proposto no curso em questão e evidenciam a não homogeneidade e a ideologia como traços constitutivos do discurso, objeto de análise da teoria formulada por Michel Pêcheux.
\end{abstract}

PALAVRAS-CHAVE: Material de inglês; Currículo oficial do estado de São Paulo; Análise de Discurso de linha francesa.

\begin{abstract}
The purpose of this paper is to analyze the meanings produced by English teachers in public schools in São Paulo state, who participate in a class of a blended specialization course, about the English teaching materials distributed by the State Department of Education. Grounded on the theoretical perspective of French Discourse Analysis, we aim to understand what English teachers think about the material with which they work in their classes and analyze the subject-positions they occupy in this context. The data analyzed consist of posts taken from a virtual forum proposed in the referred course and evidence the non homogeneity and the ideology as constitutive traits of discourse, which is the object of analysis of the theory formulated by Michel Pêcheux.
\end{abstract}

KEYWORDS: English material; Official curriculum of São Paulo State; French Discourse Analysis.

\section{INTRODUÇÃO}

Nunca sabemos quando somos sinceros. Talvez nunca o sejamos.

E mesmo que sejamos sinceros hoje, amanhã podemos sê-lo por coisa contrária.

(Bernardo Soares)

A escolha do excerto de Bernardo Soares, heterônimo de Fernando Pessoa, como epígrafe para este artigo, não é casual. O poeta português, cuja obra se constitui sob a assinatura dele mesmo e de seus heterônimos, revela a complexidade e a multiplicidade de sentidos por meio dos quais nos expressamos. A intenção aqui não é analisar o excerto retirado do Livro do Desassossego, mas apenas provocar 
uma interpretação de que nossas palavras têm seus sentidos modificados à medida que nos movimentamos no tempo, no espaço e nas relações que estabelecemos com as pessoas e com a realidade. Considerando o que diz a voz do texto de Soares sobre os movimentos que levam a uma ou outra interpretação dessa sensação volante da sinceridade, atrevemo-nos a pensar em outras instâncias para as quais essa ideia pode ser evocada e relacionamos a epígrafe acima ao objeto de estudo deste artigo: os efeitos de sentido produzidos por diferentes posições-sujeito que se constituem no contexto aqui analisado.

A partir da perspectiva da Análise de Discurso de linha francesa, teorizada por Michel Pêcheux na década de 1960, temos por objetivo geral neste trabalho analisar os sentidos a respeito do uso de materiais didáticos de inglês nos discursos de professores da Secretaria de Estado da Educação de São Paulo (doravante SEESP) em um fórum de discussão online. Para isso, será considerado um corpus constituído de postagens feitas por professores de inglês da rede pública do estado de São Paulo e por sua tutora, em um fórum de discussão de um ambiente virtual de aprendizagem que abriga um curso de especialização lato senso do qual esses professores participam.

O curso foi oferecido em duas edições, de 2010 a 2011 e de 2011 a 2012, gratuitamente para professores da rede estadual paulista de todas as disciplinas do currículo em uma parceria entre a Secretaria e as universidades estatuais do estado de São Paulo. Foram atendidos professores e gestores das escolas que se inscreveram e foram selecionados de acordo com critérios estabelecidos pela SEESP. No contexto ao qual este artigo se refere, analisamos uma turma da primeira edição do curso de especialização de inglês, que teve como ambiente virtual de aprendizagem a plataforma TelEduc ${ }^{1}$.

Para situar historicamente o objeto de análise deste artigo, é importante esclarecer algumas ações realizadas pela SEESP quando começou a implementar o que hoje é conhecido como Currículo Oficial da Rede Pública Paulista. No final do ano de 2007, foi lançado o programa São Paulo faz Escola, divulgado no site ${ }^{2}$ oficial da SEESP. Uma das ações iniciais desse programa foi coletar dos professores da rede depoimentos de práticas bem sucedidas em suas respectivas salas de aula e escolas, as quais eram postadas nesse espaço virtual de modo que fossem compartilhadas entre todos que acessassem o referido espaço.

A participação dos professores e gestores era voluntária e visava a criar uma rede de compartilhamento dessas práticas bem sucedidas entre os professores das escolas, bem como a possibilitar que esses relatos de experiência inspirassem a elaboração de um material didático que seria produzido posteriormente. Justamente devido ao fato de o acesso e a publicação dessas práticas não terem tido um caráter obrigatório, é possível que muitos professores não tenham se inteirado dessa iniciativa da Secretaria e, portanto, tenham até deixado de dela participar ${ }^{3}$.

\footnotetext{
${ }^{1}$ Para maiores informações sobre o Teleduc, vide http://hera.nied.unicamp.br/pagina/principal/. Acesso em: 16 março 2011.

${ }^{2}$ www.educacao.sp.gov.br. Acesso em: 16 março 2011.

${ }^{3}$ Esse caráter "não obrigatório" e o sentido que ele evoca de que, se não for obrigatório, os professores não participarão da atividade em questão, provocaria uma ampla discussão que não será aqui desenvolvida pelos limites que nos propusemos a analisar neste artigo.
} 
Simultaneamente a essa ação voltada aos professores, havia uma equipe de especialistas das diferentes áreas do conhecimento ${ }^{4}$ preparando um material que seria distribuído para todas as escolas da rede pública estadual de ensino no ano letivo de 2008. Esse material seria constituído de dois documentos: um que recebeu o nome de Proposta Curricular para cada disciplina do currículo e outro chamado de Caderno do Professor, também para cada uma dessas disciplinas.

Em meados do ano letivo de 2008, a SEESP distribuiu esse material para todas as escolas da rede pública estadual, a fim de que houvesse um estudo e uma familiarização dos profissionais da educação (professores e gestores) com relação aos princípios norteadores do que se chamou de Proposta Curricular bem como uma análise dos Cadernos do Professor, simultaneamente ao uso deste material em sala de aula com os alunos. É importante ressaltar que, no primeiro ano em que esses materiais foram distribuídos, 2008, apenas os professores receberam os cadernos, que traziam os princípios norteadores da então nova proposta curricular, e deveriam trabalhar as atividades sugeridas com os alunos.

Durante o ano de 2008, ficou aberto um canal de comunicação no site da SEESP para que os professores que estavam diretamente lidando com o material postassem suas críticas e sugestões às atividades contidas especialmente nos Cadernos do Professor. A maior crítica dos professores com relação ao novo material era a dificuldade que tinham em realizar as atividades propostas sem o material destinado aos alunos, que só seria produzido para o ano seguinte.

No ano de 2009, o material da SEESP foi, então, editado com algumas alterações pequenas e passou a ser acompanhado desse material que foi chamado de Caderno do Aluno. A chamada Proposta Curricular de 2008 passou a ser chamada de Currículo em 2009 e ganhou nova edição em 2010, com o novo nome e o mesmo conteúdo. Os Cadernos do Professor e os Cadernos do Aluno continuam sendo produzidos e distribuídos até hoje, e sofreram apenas alterações de imagens utilizadas devido ao vencimento de contratos de direitos autorais.

A proposta da SEESP era, portanto, a de que todos os alunos que estudassem na rede pública estadual de ensino passassem a ter o mesmo material - os Cadernos do Aluno, fundamentados pelos Cadernos do Professor - como base para o desenvolvimento de seu currículo oficial. Materiais extras, como o livro didático distribuído pelo Ministério da Educação e da Cultura (MEC), seriam bem-vindos para complementarem as atividades propostas nos Cadernos do Professor e do Aluno. De qualquer forma, porém, houve grande esforço da SEESP, por vezes manifestado como imposição de gestores de algumas escolas e órgãos centrais, para que os professores trabalhassem em suas aulas prioritariamente os materiais que compõem o currículo oficial.

\footnotetext{
${ }^{4}$ Ciências da Linguagem e suas Tecnologias (Língua Portuguesa, Inglês, Arte e Educação Física); Ciências Humanas e suas Tecnologias (História, Geografia, Sociologia e Filosofia); Ciências da Natureza e suas Tecnologias (Ciências, Física, Química e Biologia) e Matemática e suas Tecnologias.
} 


\section{FUNDAMENTAÇÃO TEÓRICA}

Tudo que existe existe talvez porque outra coisa existe. Nada é, tudo coexiste: talvez assim seja certo.

(Bernardo Soares)

A Análise de Discurso de linha francesa teve início com os trabalhos de Michel Pêcheux publicados no livro Análise Automática do Discurso (AAD), de 1969. A partir daí, pudemos observar uma mudança na maneira de analisar a língua. Pêcheux propõe que a língua seja analisada considerando-se o histórico e o social e tendo o discurso como objeto de análise.

Na perspectiva da teoria que fundamenta este trabalho, o discurso é algo que vai além da transmissão de informação e, para Pêcheux (2010), é compreendido como "efeito de sentido entre locutores." O discurso se apresenta como a materialidade da ideologia, trazendo para as análises linguísticas o social e o histórico indissociados (PÊCHEUX \& FUCHS, 2010; ORLANDI, 1994). Nessa perspectiva, a comunicação não é, portanto, linear, transmitida por meio de um código, do emissor para o receptor, como antes se entendia no Estruturalismo de Saussure e Jackobson. Ao contrário, na Análise de Discurso, a comunicação pressupõe "Efeitos que resultam da relação de sujeitos simbólicos que participam do discurso, dentro de circunstâncias dadas. Os efeitos se dão porque são sujeitos dentro de certas circunstâncias e afetados pelas suas memórias discursivas." (ORLANDI, 2006, p. 15), pelo já-dito, pelo interdiscurso.

No contexto em que este trabalho se insere, conforme apresentamos na introdução, os sujeitos que dele participam enunciam seu discurso em uma situação dada a partir de relações de sentidos entre os enunciadores, constituindo-se, desta forma, como parte das condições de produção desse discurso. São locutores que, inicialmente, enunciam da posição de alunos, uma vez que se trata de um curso de especialização do qual participam. No entanto, em alguns momentos, eles não conseguem se distanciar da posição de professores, que os constitui ideologicamente, e essas marcas aparecem na formulação dos discursos analisados. Isso também pode ser notado nos discursos aos quais a tutora se filia, já que ela não se separa das diferentes posições que ocupa: representante da SEESP e professora da rede pública.

Orlandi entende que as condições de produção do discurso incluem não apenas os sujeitos, mas também a situação. Com relação à situação, ela pode ser pensada tanto em sentido estrito, compreendendo as "circunstâncias da enunciação, o aqui e o agora do dizer, o contexto imediato" (ORLANDI, 2006, p. 15), quanto em sentido lato, isto é, compreendendo o contexto sócio-histórico, ideológico, mais amplo. Orlandi esclarece que, ainda que separemos a situação nos dois sentidos nos quais ela pode ser compreendida, essa separação, na prática, inexiste.

Assim, no caso dos professores de inglês, cujas postagens em um fórum de discussão são objeto de nossa análise, é preciso considerar tanto o contexto imediato quanto o contexto sócio-histórico ideológico mais amplo. O contexto imediato é o fórum de discussão do curso de especialização em questão. Já o contexto sócio-histórico ideológico compreende o lugar de atuação 
dos professores, ou seja, as escolas públicas estaduais, que são parte de uma organização maior gerida pela SEESP e que representam uma parcela da sociedade cujos filhos lá estudam. Ainda nesse contexto mais amplo, é preciso considerar o papel que o professor desempenha na instituição, o imaginário e o real dessa figura na mídia, na comunidade e na própria escola, além das relações hierárquicas e institucionais que fazem parte do contexto das escolas. É a partir das relações sociais que funcionam no discurso que se constituem as formações imaginárias, que, para Pêcheux (2010), "designam o lugar que A e B se atribuem cada um a si e ao outro, a imagem que eles se fazem de seu próprio lugar e do lugar do outro." (p. 81). Dessas formações imaginárias dependem as condições de produção dos discursos, as quais são modificadas em função da imagem que se projeta do outro e de si próprio em um dado contexto.

Para Orlandi, "Há em toda língua mecanismos de projeção que permitem passar da situação sociologicamente descritível para a posição dos sujeitos discursivamente significativa." (1994, p. 56). Pensando nos participantes deste estudo como posições-sujeito que serão analisadas neste trabalho, entendemos, com Orlandi, que

O sujeito da análise de discurso não é o sujeito empírico, mas a posição sujeito projetada no discurso. Isto significa dizer que há em toda língua mecanismos de projeção que nos permitem passar da situação sujeito para a posição sujeito no discurso. Portanto, não é o sujeito físico, empírico que funciona no discurso, mas a posição sujeito discursiva. O enunciador e o destinatário, enquanto sujeitos, são pontos da relação de interlocução, indicando diferentes posições sujeito. (ORLANDI, 2005, p. 15).

Assim, tendo como pressuposto essa noção de sujeito, não mais entendido como origem dos sentidos, mas interpelado social e historicamente pela ideologia e ocupando uma posição na relação com as situações discursivas, analisaremos as posições ocupadas pelos professores cursistas que fizeram as postagens no fórum de discussão, posicionando-se de maneira contrária aos materiais da SEESP.

Como já mencionado acima, eles ora ocupam a posição-sujeito de alunos (no curso de especialização), ora a de professores (ao se posicionarem sobre o material com o qual trabalham como professores). Embora eles sejam alunos de um curso de especialização e façam as postagens como locutores individuais, o enunciador desses discursos, muitas vezes, aparece na posição de professor, ainda que lhes seja solicitado (sobretudo como no fórum em questão) que enunciem da posição de alunos. Isso corrobora a tese de que, ao recorrer ao já-dito, o sujeito ressignifica e significa, não ocupando um lugar para si a priori, mas transformando-se no interdiscurso. (ORLANDI, 2007, p. 88).

Sendo assim, nosso recorte de análise constará de enunciados que são produzidos por locutores individuais em primeira pessoa, como alunos do curso de especialização, que enunciam da posição de professores, uma vez que, ideologicamente, por meio das relações de força e do imaginário, eles não conseguem se desvincular da ideologia que marca sua posição-sujeito de professores para enunciar da perspectiva de alunos. Além disso, voltaremos também o olhar para o lugar enunciativo ocupado pela tutora desses professores cursistas, que, assim 
como eles, também não consegue desocupar o lugar enunciativo de representante da SEESP. Desse modo, é possível perceber que o discurso da SEESP se faz presente nas postagens em que a tutora medeia a discussão no fórum em questão em uma relação de força com seu discurso de professora da rede pública, outra posição-sujeito ocupada por ela.

Tendo em vista que a interpretação na Análise de Discurso está ligada à questão da ideologia, nosso intuito é também analisar posicionamentos ideológicos constituídos no (inter)discurso dos professores de inglês e da tutora do curso a partir dos sentidos sobre o material de inglês distribuído pela SEESP.

Na perspectiva teórica inaugurada por Pêcheux, a compreensão de ideologia é fortemente influenciada pelas formulações de Althusser (1980) sobre as "ideologias particulares", materializadas pelos aparelhos ideológicos do Estado. Para Althusser (1980), a ideologia pode ser entendida como "uma representação da relação imaginária dos indivíduos com suas condições reais de existência" (p. 77). Filiando-se à perspectiva althusseriana segundo a qual a ideologia interpela os indivíduos em sujeitos, Pêcheux (2010) acrescenta que se deve "conceber o discursivo como um dos aspectos materiais do que chamamos de materialidade ideológica" (p. 163). Portanto, o discurso é, como já mencionamos acima, a materialidade da ideologia, a qual, para Pêcheux (2009), "fornece a 'cada sujeito' sua 'realidade', enquanto sistema de evidências e de significações percebidas aceitas - experimentadas" (p. 144).

Desse modo, a questão da ideologia, cujo trabalho é, segundo Orlandi (2005, p. 46), "produzir evidências, colocando o homem na relação imaginária com suas condições materiais de existência," é fundamental para a constituição do sujeito e dos sentidos, uma vez que "o indivíduo é interpelado em sujeito pela ideologia para que se produza o dizer.” (ORLANDI, 2005, p. 46).

Não se pretende aqui procurar o "verdadeiro" sentido desses dizeres sobre os materiais da SEESP, até porque isso não condiz com o que faz um analista de discurso. Ao contrário, pretendemos, em nossas análises, construir um dispositivo de interpretação que

tem como característica colocar o dito em relação ao não dito, o que o sujeito diz em um lugar com o que é dito em outro lugar, o que é dito de um modo com o que é dito de outro, procurando ouvir, naquilo que o sujeito diz, o que ele diz, mas que constitui igualmente o sentido de suas palavras (ORLANDI, 2005, p. 59).

Assim, na análise dos discursos dos professores, a propósito é o de perceber que "todo enunciado é intrinsecamente suscetível de tornar-se outro, diferente de si mesmo, se deslocar discursivamente de seu sentido estrito para derivar para um outro" (PÊCHEUX, 2008, p. 53). Esse “outro", para Orlandi (2005), "é o lugar da interpretação, manifestação do inconsciente e da ideologia na produção dos sentidos e na constituição dos sujeitos." (p. 59). Isso significa reconhecer que "o outro do enunciado" também é constituído pelas memórias discursivas, pelo interdiscurso, por aquilo que já foi dito e de que podemos nem ter consciência, mas que acompanha todo dizer. "O interdiscurso disponibiliza dizeres que afetam o modo como o sujeito significa em uma situação discursiva dada.” (ORLANDI, 2005, p. 31). 
Ao abordarmos a noção de interdiscurso, consideramos possível estabelecer uma relação com o excerto de Bernardo Soares, retirado também do Livro do desassossego, que iniciou a seção de fundamentação teórica deste artigo: "Tudo que existe existe talvez porque outra coisa existe. Nada é, tudo coexiste: talvez assim seja certo." Afinal, o que nossas análises procurarão evidenciar é a relação entre os dizeres dos participantes da pesquisa e essa "outra coisa" que existe e que aparece marcada ideologicamente pelas diferentes posições-sujeito que ocupam e aparecem em seu discurso. Tal relação de coexistência no discurso é, portanto, indissociável e se produz a partir do já dito, do interdiscurso, que mobiliza, afeta e modifica as relações de sentido porque/à medida que outra coisa existe.

\section{ANÁLISE}

O fórum virtual de onde as postagens foram retiradas tinha como objetivo discutir a abordagem gramatical no ensino de língua estrangeira, levando os cursistas a trazerem reflexões sobre o modo como seus professores conduziam as aulas de inglês das quais eram alunos. Mesmo diante dessa proposta, que não incluía a discussão sobre o material distribuído pela SEESP, acabou surgindo esse tema polêmico, em um contexto no qual esses cursistas assumem a posição de professores e não mais de alunos de inglês como língua estrangeira, momento que, de acordo com a proposta inicial do fórum, deveria ser o alvo da discussão.

Neste artigo, limitar-nos-emos a analisar alguns sentidos negativos, ou seja, postagens que trazem posicionamentos desfavoráveis ao material didático distribuído pela SEESP. Tal escolha deve-se ao fato de que tais postagens mobilizaram mais a intervenção da tutora dessa turma de cursistas do que as postagens nas quais eles evidenciavam apoio ao material em questão. Desse modo, é interessante observar o discurso da tutora, construído de modo a tentar minimizar as críticas, procurando uma aparente, porém impossível, neutralidade, por ocupar a posição de representante da SEESP, ao mesmo tempo em que esse discurso é também sobreposto por aquilo que ela enuncia da posição-sujeito de professora da rede pública.

Por se tratar do primeiro fórum do curso de especialização em questão, a discussão acerca do material distribuído pela SEESP - também chamado, não de maneira neutra, de apostilas, revistas e cadernos do governo pelos cursistas pode ser interpretada como um espaço de escuta que encontraram para deixar sua opinião sobre um material para cuja construção eles foram supostamente consultados. O advérbio marca a dúvida deixada oposição do discurso da SEESP em relação a postagens ${ }^{5}$ como esta, abaixo, feita pelo cursista Milton ${ }^{6}$.

\footnotetext{
${ }^{5}$ Os trechos das postagens foram reproduzidos aqui, mantendo-se o modo exato como foram publicadas nos fóruns por seus autores.

${ }^{6}$ Os nomes foram trocados a fim de preservar a identidade dos professores.
} 
Milton: Ana Maria,concordo com tudo o que você disse, porém faltou falar sobre a escolha dessas apostilas, temáticas e dos conteúdos. Diferentemente dos livros de inglês que vão ser adotados a partir de 2011 e que foram previamente escolhidos pelos professores da área, as apostilas apesar de terem sido elaboradas por uma série de pessoas notáveis, serem coerentes e seguirem uma sequência didática, não foram sequer apresentadas aos professores da rede para uma análise prévia. Posteriormente em 2008, ano da publicação e uso, a SEE abriu um link para sugestões da mesma. porém não houve nenhuma modificação. Uso a apostila de forma integral, foi ótimo padronizar o ensino, principalmente para os alunos que são transferidos de uma escola para outra e aqueles professores que não tinham o hábito de programar suas aulas, penso que após a adoção delas, precisaram se preparar melhor, mas o que me incomoda é o fato de não sermos consultados sobre a elaboração delas, parece que não fazemos parte desse processo. (Grifos nossos).

Embora reconheça que houve, por parte da SEESP, uma tentativa de incluir os professores na elaboração do material que seria posteriormente utilizado por eles, o cursista Milton evidencia em sua postagem que os professores não foram consultados e, portanto, sente que não fez parte desse processo. Sente-se à margem da implementação do material cujo destino final é ser usado por ele, professor de inglês em uma escola estadual.

Ao se colocar (ou ser colocado) na posição de professor que não é sequer consultado sobre o material com que trabalhará, e que muito menos poderá produzir $^{7}$, a postagem de Milton evoca o que Orlandi chama de sentido mais amplo, ideológico da situação (que constitui o contexto de produção do discurso juntamente com o sujeito), conforme já mencionamos acima. O que está contido nessa postagem, por meio da posição-sujeito de professor ocupada por Milton no enunciado, é o discurso dos professores da rede, que, como ele, estão à margem das decisões de órgãos centrais administrativos como a SEESP. Nesse sentido, pensando a questão da ideologia com Orlandi, entendemos que

[...] também a relação com o mundo é constituída pela ideologia; a ideologia é vista como o imaginário que medeia a relação do sujeito com suas condições de existência. No discurso, o mundo é apreendido, trabalhado pela linguagem e cabe ao analista procurar apreender a construção discursiva dos referentes. A ideologia é, pois, constitutiva da relação do mundo com a linguagem, ou melhor, ela é condição para essa relação. (ORLANDI, 1994, p. 56).

Percebemos, no espaço reivindicado por Milton, outros discursos, de seus colegas, que também ocupam o lugar de professores, e do imaginário, em oposição às "pessoas notáveis" que elaboraram o material. Ele reproduz o sentido do que está implícito ideologicamente em outros discursos, de que existe uma oposição entre quem tem autoridade para fazer o material ("notáveis") e quem fica simplesmente com a função de usá-lo (professores), sem sequer ser consultado a respeito desse uso.

${ }^{7}$ A Secretaria de Estado da Educação do Paraná adotou materiais didáticos produzidos pelos próprios professores da rede pública de ensino. O acesso aos materiais de língua estrangeira moderna pode ser feito no endereço eletrônico http://www.diaadiaeducacao.pr.gov.br/diaadia/diadia/arquivos/ File/livro_e_diretrizes/livro/lem/seed_lem_esp_ing.pdf. 
Como resposta à postagem de Milton, a tutora do curso, Milena, tem um discurso de defesa do que a SEESP afirma ter feito com relação aos canais abertos com o professor a fim de modificar o material em questão:

Milena (tutora): Oi, Milton, Segundo a SEESP, a elaboração desse material foi pensada a partir dos relatos de práticas de ensino bem sucedidas postadas pelos professores da rede no site do São Paulo faz Escola em 2007. Em uma oportunidade que tive de contatar as autoras dos materiais de inglês, foi dito que as alterações sugeridas pelo link disponibilizado em 2008 estavam sendo consideradas. No entanto, ao que parece, as alterações foram mais de ordem de correções e revisão dos materiais, além da disponibilização de gabaritos. (Grifos nossos).

A posição-sujeito ocupada pela tutora indica uma preocupação em reproduzir o discurso oficial da SEESP, talvez pelo fato de estar atuando, na época em que os dados foram coletados, como Professora Coordenadora da Oficina Pedagógica em uma Diretoria de Ensino, órgão regional da SEESP ${ }^{8}$, ou talvez ainda pela possível necessidade de minimizar o efeito de certos temas polêmicos, como a opinião sobre o material em questão.

No entanto, a tutora tenta desvincular de si mesma o discurso da SEESP, procurando uma aparente neutralidade em relação à reclamação do cursista Milton de que os professores não haviam sido consultados sobre o material em questão ("Segundo a SEESP"). Assim, ao mesmo tempo em que evidencia a posição da SEESP na resposta dada a Milton, a tutora relativiza - e se desvincula de - tal posição ao escolher a voz passiva ("foi dito que...") para se referir a algo que supostamente foi feito. Interpretamos tal estratégia como uma possível tentativa de se eximir de quaisquer que tenham sido as medidas adotadas pela instituição com relação às críticas apontadas por Milton.

Logo em seguida, a tutora concorda com o cursista e reconhece que as mudanças realizadas no material não foram feitas de acordo com as sugestões postadas pelos professores no espaço virtual destinado a isso. $\mathrm{O}$ discurso da SEESP, marcado pela posição-sujeito da tutora como representante do órgão, acaba sendo sobreposto por outra posição-sujeito que ela ocupa como professora da rede pública, ao concordar com Milton, que compartilha com ela a mesma posição enunciativa de professor.

Isso evidencia o que diz Cazarin, apoiando-se em Mariani (1998) sobre a não homogeneidade do discurso:

A prática discursiva mostra que o sujeito, quando fala, adere à formação discursiva em que está inscrito; entretanto, dentro desta, apesar de ela "determinar o que pode e deve ser dito, há, ou pode haver, efeitos de contradição", pois, conforme Mariani (1998, p. 25), assim como não há um sujeito pleno, também não há assujeitamento pleno. A maneira como a posição-sujeito se relaciona com a forma-sujeito revela a não homogeneidade da formação discursiva e, conseqüentemente, do discurso. Registro que, em $\mathrm{AD}$, não se trata apenas de pensar a heterogeneidade pelo fato de que ela é constitutiva de todo e qualquer discurso, mas, em especial, de entender que a mesma resulta da coexistência de diferentes posições-sujeito no interior de uma mesma FD [...]. (CAZARIN, 2011).

\footnotetext{
${ }^{8}$ Esta informação foi obtida do perfil da tutora na plataforma virtual de aprendizagem.
} 
Nas postagens das cursistas Sara, Berenice e Ana Maria, também é possível identificar a posição-sujeito de professoras, ao criticarem o material da SEESP. Isso fica bastante claro quando Berenice faz referência a sua iminente aposentadoria e Sara e Ana Maria mencionam seus alunos de inglês nas postagens abaixo:

\begin{abstract}
Berenice: Olá Pietra. Eu também estou ansiosa com a novidade que teremos para 2011 com o livro didático (pena que vou me aposentar e desfrutarei pouco). Até que enfim fomos lembrados, pois como sabemos nunca tivemos livro nem outro tipo de material de apoio, exceto os cadernos do governo que vieram em 2008 e que, na minha opinião, possuem textos descontextualizados, poucas ilustrações e conteúdo repetitivo em todos os volumes.
\end{abstract}

Sara: Observando os alunos e analisando percebo que eles nao gostam desse material (revista) e verbalizam isso de forma muito clara.

Ana Maria: A maioria dos alunos não gosta dos cadernos do governo e não é difícil saber o porquê. Não sei se todos os professores concordam, mas quase sempre eles são descontextualizados, as atividades são elaboradas com o pretenso objetivo de trabalhar com a questão do gênero, mas na maioria das vezes, foca pontos gramaticais. A diagramação é pobre, sem figuras e com textos grandes, não autênticos, muitos de difícil compreensão. É claro que um livro didático por si só não vai grantir o aprendizado da língua, mas pode nos dar apoio para seguir o conteúdo dos cadernos. (Grifos nossos).

A postagem de Berenice, que evidencia sua posição-sujeito de professora, aponta o livro didático como um aliado na sala de aula com alunos de inglês ("Até que enfim fomos lembrados"). Essa forma de enunciar o livro didático evoca sentidos positivos ("pena que vou me aposentar") em oposição aos sentidos negativos provocados pelo único material de apoio que os professores tiveram até então: “os cadernos do governo." É bastante significativo o modo como Berenice se refere aos materiais, chamando-os dessa forma, uma vez que estão implícitos os sentidos do imaginário de que, se algo é "do governo", não é bom: a imagem veiculada e constatada no Brasil hoje é a da precariedade do sistema de saúde, representado pelos "hospitais do governo" e da baixa qualidade da educação, representada pelas "escolas do governo". Da mesma forma, os "cadernos do governo" também não satisfazem as necessidades pedagógicas que a cursista, da posição-sujeito de professora, postula ("textos descontextualizados, poucas ilustrações e conteúdo repetitivo"). Assim como Milton, Berenice evidencia sua insatisfação com relação ao distanciamento entre os materiais e aqueles que os usam: os cadernos não são dos professores; são "do governo", em oposição irônica ao discurso do governo, que chama os materiais de "cadernos do professor e do aluno".

Berenice enuncia da posição de locutora individual ("na minha opinião") que considera o material ruim, embora saibamos, pela Análise de Discurso, da impossibilidade de um discurso individual, construído por um sujeito que não tenha sido interpelado pela ideologia. Ainda que inconscientemente, o dizer de Berenice está marcado pelo interdiscurso, e a forma de enunciar a crítica ao material (na primeira pessoa do singular) evidencia que, naquela situação 
discursiva, ela assume claramente seu posicionamento sobre o material, sem, no entanto, deixar de se filiar ao discurso de seus colegas professores. Embora use, no fim da postagem, a primeira pessoa do singular, no início ela se vale da primeira pessoa do plural, ratificando a posição-sujeito de professora e assumindo o discurso da classe: [eu e os meus colegas professores] teremos [o livro didático], "fomos lembrados, pois como sabemos nunca tivemos livro nem outro tipo de material de apoio." (grifos nossos).

A postagem de Berenice difere das postagens de Sara e Ana Maria, no sentido de que estas recorrem a seus respectivos alunos para corroborarem as críticas que elas, da posição-sujeito de professoras, também têm com relação ao material, que Sara chama de "revista" e Ana Maria, assim como Berenice, de "cadernos do governo". Portanto, não são (só) elas que não gostam do material, mas também seus alunos.

Ana Maria parece chamar os colegas cursistas para, junto com ela, ocuparem a posição-sujeito de professores. Ao dizer "Não sei se todos os professores concordam", ela os chama para o debate sobre os "cadernos do governo." Sua postagem parece polemizar mais do que a de Milton, até pelo número de respostas que obteve, superior ao do colega. Ao fazer uso de palavras carregadas de sentidos negativos (descontextualizados, diagramação pobre, sem figuras, textos grandes, não autênticos, difícil compreensão), Ana Maria marca bem seu posicionamento desfavorável ao uso desse material, mas vê no livro didático um apoio para "seguir" o conteúdo dos cadernos.

É interessante observar que, ainda que seja contrária ao material da SEESP, no fim da postagem, Ana Maria parece estar numa situação de conflito com aquela enunciada inicialmente, uma vez que "segue" os conteúdos dos cadernos. Ela não concorda com o material elaborado e distribuído pela SEESP, tem críticas contundentes a ele, mas, apesar disso, "segue-o".

A posição-sujeito de professora inicialmente ocupada por Ana Maria parece ter aqui uma espécie de silenciamento do discurso crítico sobre o material. É o livro didático - e não suas críticas fundamentadas - que apoiará o uso desse material da SEESP. Mais uma vez, o material se sobrepõe à figura do professor, como evidencia a postagem de Milton. Existe um sentido de apagamento da importância do professor por ele próprio (situação em sentido imediato) e pelo(s) outro(s) nos imaginários construídos social, histórica e ideologicamente (sentido amplo).

O discurso dos professores, ao qual Ana Maria se filia quando enuncia da posição-sujeito de professora, parece sobreposto no final da postagem pelo imaginário coletivo, ideologicamente constituído, de que os professores estão sujeitos aos "notáveis" (que elaboram o material, conforme afirma Milton) e à instituição à qual estão vinculados (a SEESP), uma vez que "seguem" o material, apesar de dele discordarem.

Em resposta às críticas de Ana Maria, novamente percebemos a posição-sujeito da tutora, Milena, como representante da SEESP: 
Milena (tutora): Concordo com você, Ana Maria, quando diz que nenhum material didático em si vai garantir o aprendizado da língua. Sabemos que nenhum material é perfeito e vai atender plenamente as expectativas de professores e alunos. No entanto, considero que os cadernos de inglês distribuídos pela Secretaria de Estado da Educação de São Paulo tenham um papel importante sobretudo no ensino de inglês, porque são coerentes com a proposta de se trabalhar as competências leitora e escritora. Além disso, considero importante que os cadernos tenham uma progressão temática, com textos variados e assuntos relacionados a interesses dos alunos de acordo com sua faixa etária. Enquanto o caderno da quinta série enfoca questões relacionadas ao ambiente escolar, o caderno da terceira série EM traz questões do mundo do trabalho. É interessante ter um material de apoio para as aulas de inglês, que, como sabemos, nunca teve livros didáticos como as demais disciplinas. No currículo do estado, agora todas as disciplinas têm materiais que podem (e devem) ser usados pelo professor de modo a ampliar os conteúdos, competências e habilidades apresentados nos cadernos. Nesse sentido, materiais complementares (áudio, vídeo, textos, imagens, multimídia) são muito bem-vindos para tornar as aulas de inglês mais significativas e interessantes para os alunos. (Grifos nossos).

Novamente, a estratégia da tutora é a de, primeiramente, concordar com algum ponto tratado pelo cursista. O uso da conjunção adversativa "no entanto" marca a mudança de posição-sujeito da tutora, que passa, então, a reproduzir o discurso da SEESP. Em oposição às palavras de sentido negativo usadas por Ana Maria, Milena utiliza apenas palavras que tenham sentidos construídos ideologicamente como bons ("progressão temática", "textos variados", "interesse dos alunos"). Diante da análise da postagem da tutora, que escolhe palavras de sentido contrário ao daquelas utilizadas pela cursista, concordamos com Pêcheux, quando afirma que

[...] o sentido de uma palavra, de uma expressão, de uma proposição, etc., não existe 'em si mesmo' (isto é, em sua relação transparente com a literalidade do significante), mas, ao contrário, é determinada pelas posições ideológicas que estão em jogo no processo sócio-histórico no qual as palavras, expressões, e proposições são produzidas (isto é, reproduzidas). Poderíamos resumir essa tese dizendo: as palavras, expressões, proposições, etc., mudam de sentido segundo as posições sustentadas por aqueles que as empregam, o que quer dizer que elas adquirem seu sentido em referência a essas posições, isto é, em referência às formações ideológicas [...] nas quais essas posições se inscrevem (PÊCHEUX, 2009, p. 146-147). (Grifos do autor).

Os sentidos atribuídos pela tutora às palavras utilizadas marcam a posiçãosujeito ocupada por ela, de representante da SEESP, reiterada ainda pela importância que atribui ao fato de todas as disciplinas (até mesmo inglês) terem materiais didáticos para trabalhar com alunos, graças a uma iniciativa do órgão que representa. Depois dessa argumentação, valorizando a elaboração e a distribuição dos materiais pela SEESP, Milena ratifica que eles podem "e devem" ser utilizados pelos professores, evidenciando, assim, a obrigatoriedade implícita no discurso oficial, conforme já dissemos acima.

Novamente, no entanto, temos a não homogeneidade do discurso quando o dizer de Milena parece relativizado pela outra posição-sujeito que ocupa (a de professora da rede pública), quando diz que "materiais complementares (áudio, vídeo, textos, imagens, multimídia) são muito bem-vindos para tornar as aulas 
de inglês mais significativas e interessantes para os alunos." Nesse trecho, a tutora parece se filiar à formação discursiva dos professores, partilhando com eles o sentido de que o material da SEESP, por si só, não torna as aulas de inglês mais significativas e interessantes, como parecia sugerir anteriormente. Também a tutora, talvez interpelada inconscientemente pela ideologia dos discursos dos cursistas que ocupam a posição-sujeito de professores no fórum, encontra em outros materiais didáticos ("áudio, vídeo, textos, imagens, multimídia”), o imaginário de que poderão melhorar as aulas de inglês.

Para concluir a análise, levaremos em conta os efeitos de sentido entre os dizeres de Milena e Ana Maria nas duas postagens que seguem:

Ana Maria: Olá Gustavo, Realmente, as atividades que tratam da AFS, uma instuição que promove intercâmbios no exterior, trazem textos autênticos (nesse caso, retirados da Internet), mas vc pode observar que na maioria das atividades dos cadernos (pelo menos do EM, que são aqueles que eu trabalho) aparece algo como "elaborado especialmente para o SP faz escola". No entanto, não posso deixar de concordar com alguns autores (por ex Scarcella e Oxford, 1992; Dudley e St John, 1998; Nunan, 1999; Leffa, 2003), pois eles afirmam que um material didático deve apresentar a maior quantidade possível de textos autênticos para que o aluno possa vivenciar aquilo que circula no mundo. Além disso, de acordo com Ramos (2004), autora que apresenta uma proposta de trabalho com gêneros, é importante que os gêneros sejam autênticos para que os aprendizes possam se familiarizar com os textos e vivenciar aquilo que circula no mundo real. De qualquer maneira, trago outro autor (Day, 2004), pois ele faz uma colocação importante, ou seja, o material utilizado em sala de aula, seja ele com textos autênticos ou especialmente preparados pare o ensino de uma língua, deve ser apropriado às habilidades lingüísticas dos aprendizes - o que me leva à colocação da Milena. Embora a maioria dos textos dos cadernos não seja autêntica, também considero que os cadernos da SEE -SP mostram-se coerentes com a proposta de se trabalhar as competências leitora e escritora e têm uma progressão temática, com textos variados e assuntos relacionados a interesses dos alunos de acordo com sua faixa etária. Também considero um avanço o fato de que agora todas as disciplinas (inclusive o inglês) tenham materiais. Por fim, os cadernos, sejam considerados bons ou não, nos dão orientações sobre o que e como ensinar e, de certa maneira, facilitam o planejamento de nossas aulas. Abçs. Ana Maria. (Grifos nossos).

Milena: Oi, Ana Maria, Sempre que tenho a oportunidade de avaliar os cadernos do professor e do aluno, minha maior crítica é justamente com relação aos textos não autênticos. Concordo plenamente com você, quando postula o uso de textos autênticos, que, de fato, circulam no entorno social dos alunos. Uma das justificativas para o fato de não haver apenas textos autênticos no material da Secretaria pode estar relacionada a questões de direitos autorais. Mas, considero que, mesmo quando trabalhamos com os textos "elaborados especialmente para o São Paulo faz Escola", seja possível enfatizarmos as características dos gêneros em questão e desenvolvermos as competências priorizadas nas situações de aprendizagem. Por fim, gostaria de dizer que essas reflexões são muito importantes para aprofundarmos a compreensão do currículo de inglês e pensarmos no que pode ser melhorado. Abraços, Milena. (Grifos nossos).

Nesta postagem feita por Ana Maria, vamos priorizar o trecho sublinhado, que se refere à adesão da cursista ao discurso da SEESP, representado pela posição-sujeito da tutora como representante da instituição. No entanto, não 
poderíamos deixar de colocar o texto todo, por entendermos que o início é uma parte extremamente importante de sua argumentação e, de certo modo, expressa, a resistência que Ana Maria demonstra (e justifica) ao material. Apenas para contextualizar, no início da postagem, a cursista responde ao colega Gustavo que, de fato, o exemplo dado por ele ("as atividades que tratam da AFS") se constitui de textos autênticos, cuja ausência no material é uma de suas principais críticas. Para isso, Ana Maria, com o objetivo de dar força a sua argumentação, cita autores que corroboram sua posição a respeito da importância de textos autênticos no ensino de língua estrangeira. Com isso, ela fundamenta seu ponto de vista e evidencia que este é o discurso ao qual se filia: o discurso acadêmico que se opõe ao discurso oficial da SEESP.

Conforme constatamos na postagem de Milena, esta também é sua maior crítica. $\mathrm{Na}$ postagem da tutora, percebemos a mesma estratégia novamente: concordar com o dizer do cursista para, em seguida, justificar a posição da SEESP (a ausência de textos autênticos pode estar relacionada "a questões de direitos autorais"). Ela parece aqui ocupar a posição-sujeito de representante da SEESP, ao justificar que isto independe do órgão. Continuando a argumentação, Milena diz que, mesmo com textos não autênticos, é possível trabalhar bem com as características dos gêneros textuais trazidos no material da SEESP.

No trecho destacado da postagem de Ana Maria, temos uma adesão ao discurso da SEESP, materializado pela posição ocupada pela tutora, inclusive com o uso das mesmas palavras ("progressão temática, com textos variados e assuntos relacionados a interesses dos alunos de acordo com sua faixa etária") usadas por Milena na postagem anterior. Ainda em concordância com a tutora, que enuncia da posição-sujeito de representante da SEESP, Ana Maria também considera um avanço a existência de um material de inglês, ainda que tenha muitas críticas a ele. Neste trecho também se observa a mesma sobreposição do discurso da SEESP no discurso dos professores, materializado pela posição-sujeito de professora ocupada por Ana Maria, como aconteceu na primeira postagem da cursista. A cursista encerra a postagem reconhecendo que, embora tenha críticas e reconheça as diferentes opiniões que existem sobre os materiais (não mais chamados de "cadernos do governo", mas de "cadernos da SEE-SP"), "de certa maneira, facilitam o planejamento de nossas aulas".

A tutora finaliza sua postagem com a consideração de que as discussões realizadas no fórum contribuem para a compreensão do material e a reflexão daquilo que pode ser melhorado. Também nessa postagem, percebemos as diferentes posições ocupadas pela tutora, que, ao mesmo tempo em que traz o discurso da SEESP, ao justificar a ausência de materiais autênticos, reconhece que há o que ser melhorado nos polêmicos "cadernos do governo".

Em todos os trechos de postagens analisados, pudemos notar as diferentes posições-sujeito que se sobrepõem nos discursos aos quais a tutora e os alunos do curso de especialização se filiam. A escolha das palavras, carregadas de sentidos ideológicos, o lugar de onde falam e as diferentes filiações discursivas dos envolvidos no contexto analisado demonstram a impossibilidade de se evidenciar apenas uma posição-sujeito nos enunciados produzidos. 
O discurso, portanto, na perspectiva teórica que embasa este estudo, é carregado de sentidos ideológicos percebidos a partir de diferentes posições-sujeito ocupadas pelos produtores dos enunciados aqui analisados. Tais enunciados, como vimos, tiveram como foco um tema que sequer tinha sido proposto como objeto de discussão do fórum virtual em questão, mas que se destacou por ocupar um lugar importante para os cursistas, que falaram do lugar de professores, do qual não puderam se dissociar. Tal indissociação teve impacto direto nas intervenções da tutora com relação às postagens dos cursistas, nas quais também ficaram evidentes as diferentes posições-sujeito ocupadas por ela.

\section{CONSIDERAÇÕES FINAIS}

Em nossas análises, procuramos significar os diferentes sentidos sobre os materiais didáticos da SEESP nos discursos aos quais se filiam os cursistas e a tutora de um curso de especialização a distância. Procuramos sentidos ideológicos impregnados nos dizeres dessas pessoas pelo interdiscurso, entendido como memória discursiva, como o já-dito e esquecido, que constitui a posição-sujeito ocupada por elas: professores da rede pública estadual, no caso dos cursistas, e representante da SEESP e também professora da rede, no caso da tutora.

Procuramos, ainda, evidenciar os efeitos de sentido entre os locutores, que inserem seus discursos em formações discursivas às quais se filiam social, histórica e ideologicamente. Enfim, no contexto deste estudo, não podemos desconsiderar a situação, em sentido amplo, ideológico e histórico, da imagem que se faz do professor: é aquele que ocupa uma determinada posição na instituição de que faz parte (a escola pública, gerida pela SEESP). Essa posição, no entanto, contrasta com outra que esses professores postulam em certos momentos dos discursos aqui analisados: serem consultados e terem suas sugestões consideradas na elaboração do material, como postula Milton; terem um material ilustrado, com textos contextualizados, como pedem Ana Maria e Berenice e com textos autênticos, como argumenta Ana Maria.

Enfim, a não homogeneidade e a ideologia aparecem como traços constitutivos do discurso, objeto de análise da teoria formulada por Pêcheux. Isso pode ser observado não apenas no corpus que nos propusemos a analisar neste trabalho, mas em todo enunciado que, como vimos, está impregnado pelo interdiscurso, modificando, desse modo, as diferentes posições que um sujeito pode ocupar nas situações discursivas em que se coloca ou é colocado, como no caso da proposta do fórum de discussão de onde as postagens analisadas foram retiradas. Desse modo, compreender essas alterações de posição-sujeito é olhar para o discurso de uma perspectiva complexa que envolve reconhecer as ideologias que constituem os sujeitos, das quais eles não se dissociam nos enunciados que produzem em diferentes contextos. 


\section{REFERÊNCIAS}

ALTHUSSER, L. Ideologia e Aparelhos Ideológicos do Estado. 3. ed. Lisboa: Editorial PresençaMartins Fontes, 1980.

CAZARIN, E. A. A heterogeneidade discursiva de uma posição-sujeito. Disponível em: <http://www. ufrgs.br/analisedodiscurso/anaisdosead/2SEAD/SIMPOSIOS/ErciliaAnaCazarin.pdf>. 200? Acesso em: 14 abril 2011.

MARIANI, B. Ideologia e inconsciente na constituição do sujeito. Gragoatá, n. 5, Rio de Janeiro, EdUFF, 1998.

ORLANDI, E. P. Análise de Discurso. In: LAGAZZI-RODRIGUES, S., ORLANDI, E. P. (Orgs.). Introdução às ciências da linguagem: discurso e textualidade. Campinas, SP: Pontes, 2006, p. 13-31. . Análise de Discurso: princípios e procedimentos. 6. ed. Campinas, SP: Pontes, 2005.

. Discurso, imaginário social e conhecimento. In: Em Aberto, n.61, ano 14. Brasília: INEP, jan./ mar. 1994, 53-59. Disponível em: < http://www.rbep.inep.gov.br/index.php/emaberto/article/ viewFile/911/817>. Acesso em: 11 abril 2011.

PÊCHEUX, M. Análise automática do discurso (AAD 69). Trad.: Eni Pulcinelli Orlandi. In: GADET, F.; HAK, T. (Orgs.). Por uma análise automática do discurso: uma introdução à obra de Michel Pêcheux. Trad. Bethania S. Mariani [et al]. 4. ed. Campinas: Editora da UNICAMP, 2010, p. 59-158.

. O discurso: estrutura ou acontecimento. Trad.: Eni Pulcinelli Orlandi. 5. ed. Campinas, SP: Pontes, 2008.

. Semântica e discurso: uma crítica à afirmação do óbvio. Trad.: Eni Pulcinelli Orlandi [et al]. 4. ed. Campinas: Editora da Unicamp, 2009.

PÊCHEUX, M.; FUCHS, C. A propósito da análise automática do discurso: atualização e perspectivas (1975). Trad. Péricles Cunha. In: GADET, F.; HAK, T. (Orgs.). Por uma análise automática do discurso: uma introdução à obra de Michel Pêcheux. Trad. Bethania S. Mariani [et al]. 4. ed. Campinas: Editora da UNICAMP, 2010, p. 159-249.

PESSOA, F. Livro do desassossego. Por Bernardo Soares. Edição de Richard Zenith. Lisboa: Assírio \& Alvim, 2006. 